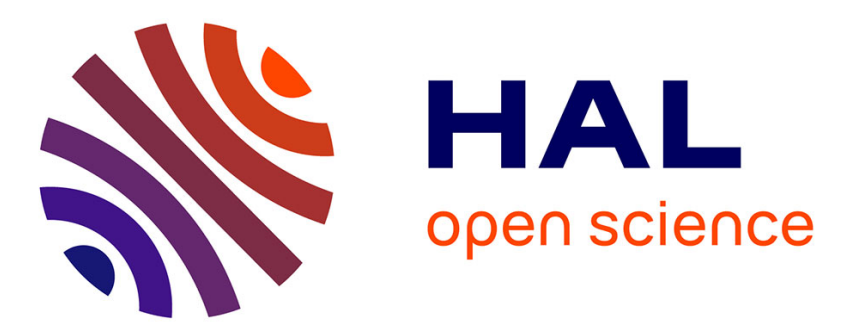

\title{
Evaluation of the Town Energy Balance Model in Cold and Snowy Conditions during the Montreal Urban Snow Experiment 2005
}

\author{
A. Lemonsu, S. Bélair, J. Mailhot, S. Leroyer
}

\section{- To cite this version:}

A. Lemonsu, S. Bélair, J. Mailhot, S. Leroyer. Evaluation of the Town Energy Balance Model in Cold and Snowy Conditions during the Montreal Urban Snow Experiment 2005. Journal of Applied Meteorology and Climatology, 2010, 49 (3), pp.346-362. 10.1175/2009JAMC2131.1 . hal-02369032

\section{HAL Id: hal-02369032 \\ https://hal.science/hal-02369032}

Submitted on 18 Nov 2019

HAL is a multi-disciplinary open access archive for the deposit and dissemination of scientific research documents, whether they are published or not. The documents may come from teaching and research institutions in France or abroad, or from public or private research centers.
L'archive ouverte pluridisciplinaire HAL, est destinée au dépôt et à la diffusion de documents scientifiques de niveau recherche, publiés ou non, émanant des établissements d'enseignement et de recherche français ou étrangers, des laboratoires publics ou privés. 


\title{
Evaluation of the Town Energy Balance Model in Cold and Snowy Conditions during the Montreal Urban Snow Experiment 2005
}

\author{
A. LEMONSU \\ Centre National de Recherches Météorologiques, Météo-France, Toulouse, France \\ S. BÉLAIR AND J. MAILHOT \\ Environment Canada, Meteorological Research Division, Dorval, Quebec, Canada
}

S. LEROYER

Atmospheric and Environmental Research Laboratory, McGill University, Sainte-Anne-de-Bellevue, Quebec, Canada

(Manuscript received 3 October 2008, in final form 25 August 2009)

\begin{abstract}
Using the Montreal Urban Snow Experiment (MUSE) 2005 database, surface radiation and energy exchanges are simulated in offline mode with the Town Energy Balance (TEB) and the Interactions between Soil, Biosphere, and Atmosphere (ISBA) parameterizations over a heavily populated residential area of Montreal, Quebec, Canada, during the winter-spring transition period (from March to April 2005). The comparison of simulations with flux measurements indicates that the system performs well when roads and alleys are snow covered. In contrast, the storage heat flux is largely underestimated in favor of the sensible heat flux at the end of the period when snow is melted. An evaluation and an improvement of TEB's snow parameterization have also been conducted by using snow property measurements taken during intensive observational periods. Snow density, depth, and albedo are correctly simulated by TEB for alleys where snow cover is relatively homogeneous. Results are not as good for the evolution of snow on roads, which is more challenging because of spatial and temporal variability related to human activity. An analysis of the residual term of the energy budget-including contributions of snowmelt, heat storage, and anthropogenic heat-is performed by using modeling results and observations. It is found that snowmelt and anthropogenic heat fluxes are reasonably well represented by TEB-ISBA, whereas storage heat flux is underestimated.
\end{abstract}

\section{Introduction}

At high latitudes and under a cold winter climate, cities may be covered by snow for several months of the year. This is notably the case for most Canadian cities. During recent years, the Meteorological Service of Canada (MSC) put special emphasis on the representation and understanding of snow processes and their influence on radiation and energy exchanges at the surface in urban areas. In this context, the Montreal Urban Snow Experiment (MUSE) 2005 (Lemonsu et al. 2008) has been conducted to document the evolution of surface characteristics as well as radiation and energy budgets in

\footnotetext{
Corresponding author address: Dr. A. Lemonsu, CNRM/GMME/ TURBAU, Météo-France, 42 Ave. Gaspard Coriolis, 31057 Toulouse CEDEX, France.

E-mail: aude.lemonsu@meteo.fr
}

a homogeneous dense urban area of Montreal (Quebec, Canada) during the winter-spring transition period (from March to April 2005).

In addition to this experimental effort, a new urban mesoscale modeling system has been developed by including an urban canopy model, the Town Energy Balance model (TEB; Masson 2000), in the physics package of MSC's atmospheric models. Over the last 10 years, such urban schemes have been developed to simulate the specific physical processes that occur in urban canopies. In particular, these schemes resolve the surface energy budget (SEB) with various degrees of complexity (Mills 1997; Best 1998; Brown 2000; Masson 2000; Kusaka et al. 2001; Grimmond and Oke 2002; Martilli et al. 2002; Vu et al. 2002; Dupont et al. 2004). Most of these models only consider sensible and storage heat fluxes and very few treat water exchanges and latent heat fluxes (Grimmond et al. 1986; Masson 2000; Dupont et al. 
2004). Except for TEB, none of the models takes into account the possible presence of snow on built covers.

TEB has already been evaluated in offline mode for various urban sites (Masson et al. 2002; Lemonsu et al. 2004; Offerle et al. 2005; Roberts et al. 2006), in each case under warm, sunny, and dry meteorological conditions. Recently, the complete MSC system, including TEB, has been run over Oklahoma City (Oklahoma) to simulate two intensive observational period (IOP) cases taken from the Joint Urban 2003 experiment (Allwine et al. 2004; Lemonsu et al. 2009). Only Pigeon et al. (2008) tested the scheme for a wintertime period, but it was without snow because this was over Toulouse (France).

The present study examines TEB's performance under cold and snowy conditions by focusing on radiation/ energy exchanges and snow cover evolution using the MUSE dataset. The main objective is to assess and quantify the impact of snow on the SEB of a North American city with a cold climate during the winter-spring transition period.

In the process of achieving this objective, special interest has been given to the analysis of the residual term of the SEB. In MUSE, a net radiation flux and turbulent fluxes of heat and humidity are experimentally estimated for the energy budget. In these conditions, the residual term includes contributions from anthropogenic heat release, snow melting, and heat storage (Lemonsu et al. 2008), which are not directly measured. A simple evaluation of these contributions is proposed here for the period including IOP1 and IOP2 (when snow measurements are available), according to two methods based on observations, ancillary data, and modeling results.

The TEB-Interactions between Soil, Biosphere, and Atmosphere (ISBA) system is presented in section 2 with specific attention to snow parameterizations. In section 3, the general framework of the simulation and the numerical setup are described, after a brief reminder on both the MUSE 2005 experiment and on the numerous data available for testing the models. Evaluation results are then presented in section 4; the first part of this section focuses on radiation and energy exchanges, whereas most of the section is concerned with the performance of TEB's and ISBA's snow parameterizations. The residual term of the energy budget is discussed in section 5, with a summary and conclusions in section 6 .

\section{Urban modeling system}

Surface radiation and energy exchanges are simulated with a surface numerical system that includes TEB and ISBA for built-up and vegetated covers, respectively. These two models are run independently and provide surface fluxes, which are then averaged according to the respective fractions of built-up and vegetated covers. The representation of snow processes in TEB and ISBA is described later.

\section{a. ISBA land surface scheme}

The land surface scheme ISBA (Noilhan and Planton 1989) represents surface processes including water and energy budgets over natural land covers. This scheme has been used in many situations and has been extensively described in the literature (Noilhan and Planton 1989; Noilhan and Mahfouf 1996; Boone et al. 1999; Bélair et al. 2003a,b). Its force-restore version, which includes three soil layers [surface, root, and deep layers, according to Boone et al. (1999)], is used in this study. A set of soil properties (e.g., soil texture and thickness, field capacity, and wilting point) and vegetation (e.g., leaf area index, albedo, emissivity, and roughness length) are prescribed as input parameters.

Here, ISBA is integrated using the snow scheme developed by Douville et al. (1995, hereinafter referred to as D95). This scheme includes physically based snow hydrology with a single surface energy budget, including contributions from fractions of snow-covered $f_{n}$ and snowfree $\left(1-f_{n}\right)$ areas. This composite surface is characterized by a single surface temperature $T_{s}$ and by averaged albedo $\alpha_{t}$, emissivity $\epsilon_{t}$, and heat transfer coefficient $C_{t}$, computed from properties of snow, vegetation, and soil. D95 solves prognostic equations for snow water equivalent $W_{n}$, snow density $\rho_{n}$, and snow albedo $\alpha_{n}$ to simulate the snowpack evolution. The variables $W_{n}$ and $\rho_{n}$ are assumed to be constant across the snowpack. The mass conservation equation is given by

$$
\partial W_{n} / \partial t=P_{n}-E_{n}-F_{n},
$$

where $P_{n}$ is the snowfall rate, $E_{n}$ is the snow sublimation rate, and $F_{n}$ is the snowmelt rate. The snow aging process is associated with compaction and deterioration of the snowpack that translates into an increase of snow density and a decrease of snow albedo. These mechanisms are parameterized in D95 using formulations based on time constants. Snow density $\rho_{n}$ increases exponentially with time [as proposed by Verseghy (1991)]:

$\rho_{n}(t+\Delta t)=\left[\rho_{n}(t)-\rho_{n}^{\max }\right] \exp \left[\rho_{n}(t)-\rho_{n}^{\max }\right]+\rho_{n}^{\max }$.

Snow albedo $\alpha_{n}$ follows an exponential decrease during the melting period (Verseghy 1991):

$$
\alpha_{n}(t+\Delta t)=\left[\alpha_{n}(t)-\alpha_{n}^{\min }\right] \exp \left(-\tau_{f} \frac{\Delta t}{\tau_{1}}\right)+\alpha_{n}^{\min },
$$

whereas it simply decreases linearly during the cold period (according to Baker et al. 1990): 


$$
\alpha_{n}(t+\Delta t)=\alpha_{n}(t)-\tau_{a} \frac{\Delta t}{\tau_{1}}
$$

In Eqs. (2)-(4), $\tau_{1}$ is a period of one day (86 $\left.400 \mathrm{~s}\right), \tau_{f}$ is a time constant set to 0.24 , which corresponds to an exponential $e$-folding time of about 4 days, and $\tau_{a}$ is another time constant set to 0.008 . Fresh snow is characterized by a minimum value of snow density $\rho_{n}^{\min }=100 \mathrm{~kg} \mathrm{~m}^{-3}$ and a maximum value of snow albedo $\alpha_{n}^{\max }=0.85$. Snow density and albedo, as parameterized in Eqs. (2), (3), and (4), are restricted by the limiting values $\rho_{n}^{\max }=$ $300 \mathrm{~kg} \mathrm{~m}^{-3}$ and $\alpha_{n}^{\min }=0.50$.

\section{b. TEB urban canopy model}

The TEB urban scheme (Masson 2000) is a single-layer urban canopy model based on a simple geometry of urban covers. Radiation and energy budgets are solved independently for roofs, roads, and walls and then aggregated for the whole urban canopy. The following mean geometric parameters describe the urban arrangement: building fraction, mean building height, roughness length for momentum, canyon aspect ratio, and the ratio between walls and horizontal built-up areas. Radiative and thermal properties of materials are associated with each specific urban facet.

The TEB model includes snow reservoirs on horizontal surfaces (i.e., roofs and roads), which intercept snowfall. This representation of snow is derived from D95, as described in the previous section, but it was modified in the following ways: 1 ) the radiation budget resolved for snow-covered fractions of roads takes into account shadow effects and multiple reflections inside the street canyon, and 2) surface energy budgets are resolved independently for snow-free and snow-covered portions of roofs and roads and then aggregated. Prognostic variables of TEB's snow parameterization are snow water equivalent $W_{n^{*}}$, snow density $\rho_{n^{*}}$, snow albedo $\alpha_{n^{*}}$, and snow temperature $T_{n^{*}}$ for roof and road (the index $*$ refers to roof or road).

The time evolution of snow properties in the urban environment is parameterized according to the same formulations as given in Eqs. (1)-(4), except for snow aging, which is accelerated in cities because of human activities (pedestrians, traffic, and pollution). Because snow darkens and densifies more rapidly than in nonurban areas, the time constants $\tau_{f}$ and $\tau_{a}$ associated with snow density and snow albedo, respectively, have been modified. These constants must be modified independently for roof and road snow reservoirs, because the impact of human activities is different at the street level and on the roofs (this will be discussed in section 4b). Finally, the version of TEB used here does not take into account the snow removal operations because there were none during the field campaign.

\section{Application of TEB-ISBA to MUSE 2005}

\section{a. MUSE 2005}

The MUSE 2005 experiment (described in Lemonsu et al. 2008) has been conducted in a homogeneous dense urban area of Montreal from 17 March to 14 April 2005. During this transition period from winter to spring conditions, snow was observed to evolve from near-total to zero fractional coverage. The urban arrangement at the observational site was composed of adjacent two- or threestory houses with flat roofs and separated by streets and alleys (see aerial photo in Fig. 1). The mean urban canopy height was approximately $9.5 \mathrm{~m}$. Each house had a backyard (partially covered by concrete), an alley side, and a small front yard streetside. About $25 \%$ of the land surface was covered by lawns and sparse trees.

A 20-m-high tower was located in a backyard of Fabre Street (Fig. 1), and it was instrumented at its top to measure incoming and outgoing short- and longwave radiation, as well as turbulent fluxes by the eddy correlation technique. An infrared camera was also installed at the top of the tower and oriented toward Fabre Street. Because of the large temperature difference between snowcovered and snow-free surfaces, measurements from the thermal camera were used to determine the snow coverage fractions. In addition, snow depth on the roof nearest to the tower was measured with a remote sensor. Two infrared thermometers provided automatic measurements of surface temperature, in Fabre Street and the alley, for the first-story brick wall.

To collect additional manual observations, four 1-day IOPs were conducted during MUSE 2005 on 18, 22, 30 March, and 5 April (see Fig. 2). Among these observations, radiative surface temperature measurements were taken hourly for various urban facets, including walls at different levels, sidewalks, and pavement in Fabre and Saint-Zotique Streets, and in the alley. Also, snow depth, density, and albedo were measured four times per day in Fabre Street and the alley (Fig. 1), as long as the snowpack was deep enough to allow measurements.

\section{b. TEB-ISBA numerical setup}

TEB-ISBA schemes are run in an offline mode for the complete experimental period, that is, from 1500 LST 17 March to 0800 LST 14 April. It is forced using a 30-min time step with short and longwave downward radiation, air pressure, air temperature, specific humidity, and wind speed, recorded at the top of the tower $\left(z_{a}=20 \mathrm{~m}\right.$ above ground level). Hourly precipitation rates are obtained from the operational meteorological station at the Montreal international airport, located in Dorval (17 $\mathrm{km}$ from the tower). 

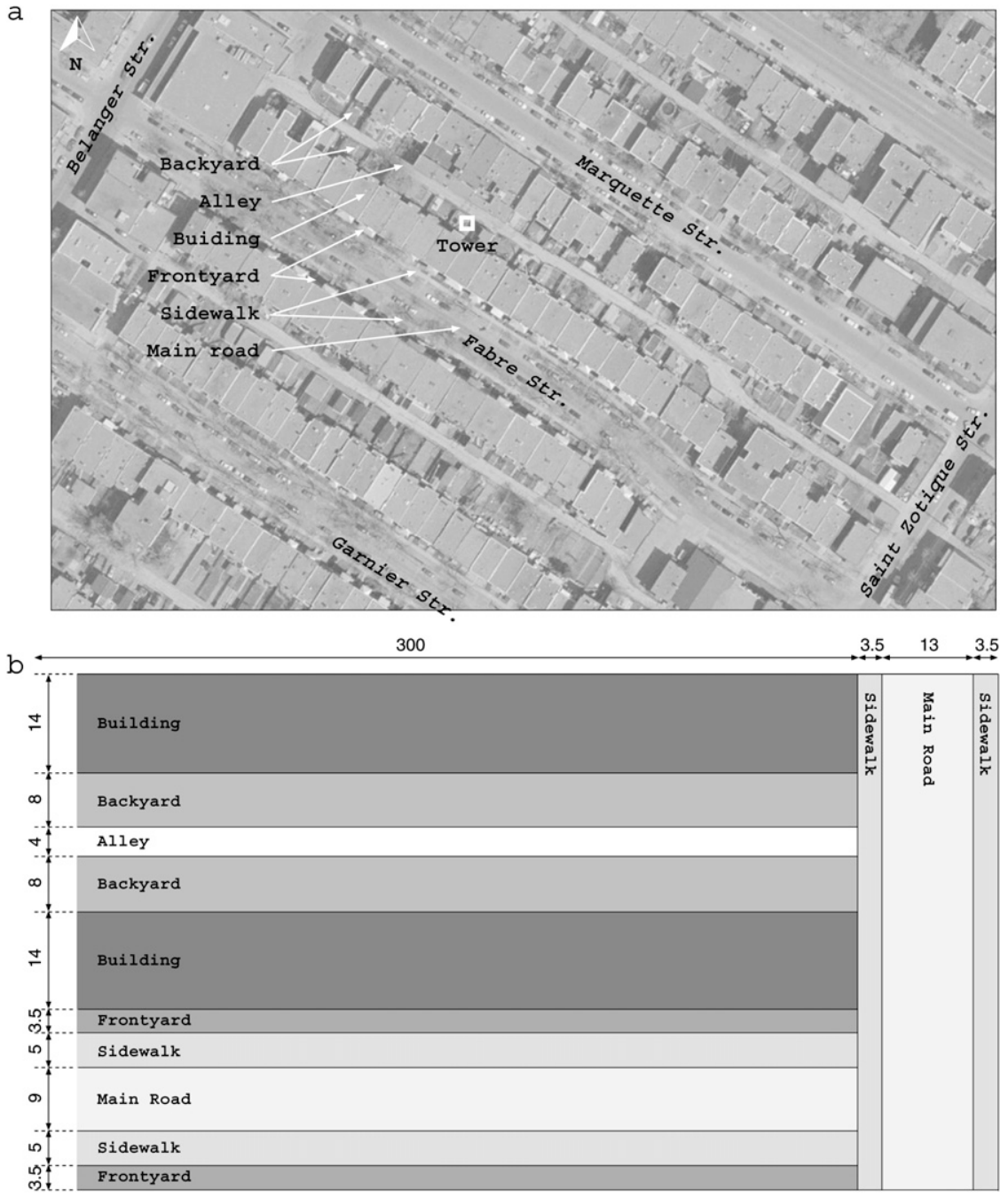

FIG. 1. (a) Aerial photograph of the study area (Source: Navigateur Urbain, city of Montreal, available online at http://www.navurb.com). (b) Simplified representation of land covers for the study area, including dimensions of the various urban elements in meters.

Atmospheric forcings are presented in Fig. 2. During the experimental period, the shortwave radiation progressively increases, in conjunction with a warming of the near-surface air as shown by the positive trends of air temperatures. It is particularly marked after 10 days of the experiment. At the beginning of the campaign, air temperatures vary from negative values at night to positive values during daytime. After $26 \mathrm{March}$, air temperatures are systematically positive with mean values of about $6^{\circ} \mathrm{C}$. Moderate winds are recorded, weaker at night (less than $2 \mathrm{~m} \mathrm{~s}^{-1}$ ) than during daytime $\left(4-6 \mathrm{~m} \mathrm{~s}^{-1}\right)$. Finally, some scattered and not very intense rainfall events are observed during the period but no snowfall event is recorded.

Lemonsu et al. (2008) showed that the source-area ground characteristics relative to turbulent flux measurements remain homogeneous during the experiment.
The TEB-ISBA schemes can, thus, be run on a single grid point using mean surface parameters describing the urban environment. The mean urban canyon concept used in TEB, however, does not fit well with the particular urban configuration of the experimental area (composed of streets and alleys that differ in their characteristics and where human activities are varied). Pedestrian and vehicle traffic circulation is concentrated mostly in the streets and is very limited in the alleys. Furthermore, the snow removal operation only takes place in the streets, which leads to a very different snowpack evolution; the snow in the streets disappears quickly, whereas it stays much longer (and untouched) in the alleys. To take into account these different characteristics in the model, two independent simulations are performed for roads $S_{\text {road }}$ and alleys $S_{\text {alley }}$, with different descriptive parameters. 

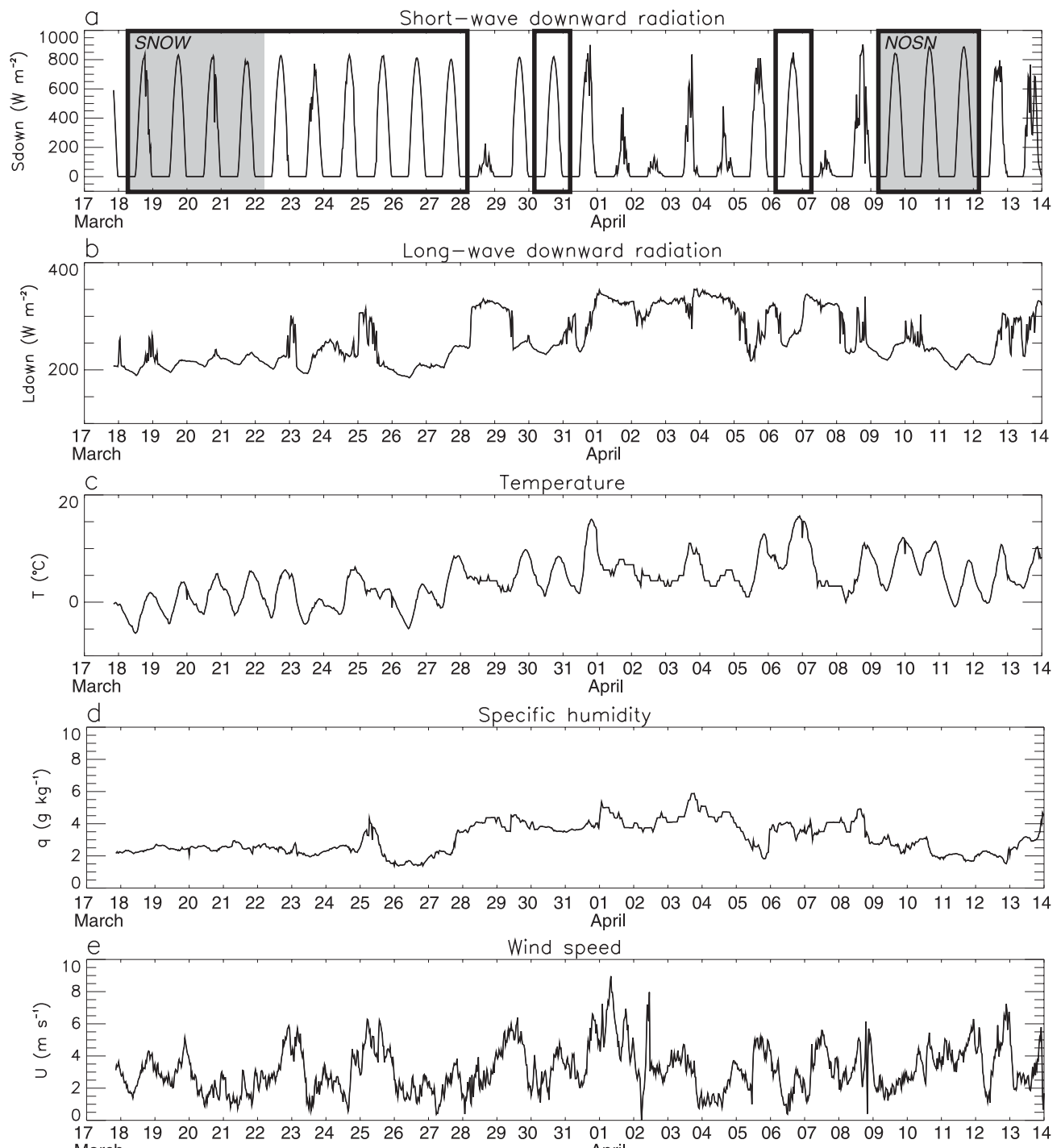

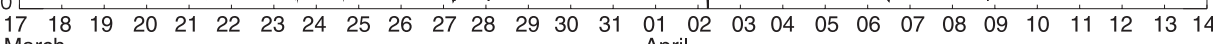
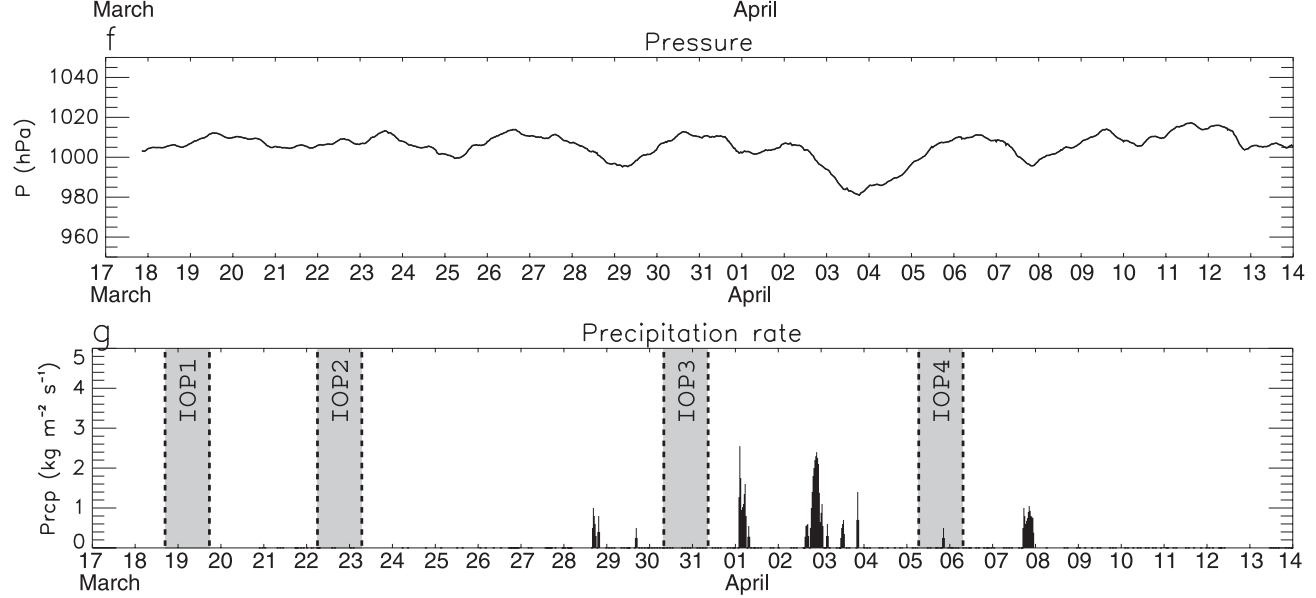

FIG. 2. Atmospheric forcings: (a) downward shortwave and (b) downward longwave radiation (W $\mathrm{m}^{-2}$ ), (c) air temperature $\left({ }^{\circ} \mathrm{C}\right),(\mathrm{d})$ specific humidity $\left(\mathrm{g} \mathrm{kg}^{-1}\right)$, (e) wind speed $\left(\mathrm{m} \mathrm{s}^{-1}\right)$, (f) pressure $(\mathrm{hPa})$, and $(\mathrm{g})$ precipitation rate $\left(\mathrm{kg} \mathrm{m}^{-2} \mathrm{~s}^{-1}\right)$. (a) The MUSE study period is delimited by black frames, whereas periods SNOW and NOSN are represented by gray areas. (g) The dates of the four IOPs are shaded. 
TABLE 1. Main TEB-ISBA input parameters for $S_{\text {Road }}$ and $S_{\text {Alley. }}$.

\begin{tabular}{|c|c|c|c|c|}
\hline Parameter & Description & Unit & $S_{\text {Road }}$ & $S_{\text {Alley }}$ \\
\hline \multicolumn{5}{|c|}{ Cover fractions } \\
\hline$f_{\text {nature }}$ & Natural cover fraction & - & 0.16 & 0.49 \\
\hline$f_{\text {built }}$ & Built cover fraction & - & 0.84 & 0.51 \\
\hline$f_{\text {water }}$ & Water fraction & - & 0 & 0 \\
\hline \multicolumn{5}{|c|}{ ISBA's input parameters } \\
\hline$f_{\mathrm{veg}}$ & Vegetation fraction & - & 0.30 & 0.30 \\
\hline$f_{\text {soil }}$ & Bare soil fraction & - & 0.70 & 0.70 \\
\hline LAI & Leaf area index & $\mathrm{m}^{2} \mathrm{~m}^{-2}$ & 0 & 0 \\
\hline$z_{0 \mathrm{~m}}$ & $\begin{array}{l}\text { Roughness length for } \\
\text { momentum }\end{array}$ & $\mathrm{m}$ & 0.024 & 0.024 \\
\hline$z_{0 \mathrm{~h}}$ & $\begin{array}{l}\text { Roughness length for } \\
\text { heat }\end{array}$ & $\mathrm{m}$ & 0.0024 & 0.0024 \\
\hline$\alpha_{\text {nat }}$ & Albedo & - & 0.20 & 0.20 \\
\hline$\epsilon_{\text {nat }}$ & Emissivity & - & 0.97 & 0.97 \\
\hline \multicolumn{5}{|c|}{ TEB's input parameters } \\
\hline$f_{\text {bld }}$ & Building density & - & 0.33 & 0.39 \\
\hline$z_{\text {bld }}$ & Mean building height & $\mathrm{m}$ & 9.5 & 9.5 \\
\hline$z_{0 \mathrm{~m}}$ & $\begin{array}{l}\text { Roughness length for } \\
\text { momentum }\end{array}$ & $\mathrm{m}$ & 1.24 & 1.24 \\
\hline$z_{0 h}$ & $\begin{array}{l}\text { Roughness length for } \\
\text { heat }\end{array}$ & $\mathrm{m}$ & 0.0062 & 0.0062 \\
\hline$\lambda_{C}$ & Wall-plane area ratio & - & 0.56 & 1.08 \\
\hline$\alpha_{\text {roof }}$ & Roof albedo & - & 0.08 & 0.08 \\
\hline$\epsilon_{\text {roof }}$ & Roof emissivity & - & 0.90 & 0.90 \\
\hline$\alpha_{\text {road }}$ & Road albedo & - & 0.16 & 0.16 \\
\hline$\epsilon_{\text {road }}$ & Road emissivity & - & 0.94 & 0.94 \\
\hline$\alpha_{\text {wall }}$ & Wall albedo & - & 0.25 & 0.25 \\
\hline$\epsilon_{\text {wall }}$ & Wall emissivity & - & 0.90 & 0.90 \\
\hline
\end{tabular}

The input parameters for TEB-ISBA provide information on built covers and vegetation properties. Except for the mean building height, which has an estimated value of $9.5 \mathrm{~m}$ according to Lemonsu et al. (2008), all geometric parameters are determined using an aerial photograph provided by the Navigateur Urbain of the city of Montreal (available online at http://www.navurb. com), together with simplified sketches of the urban arrangement (presented in Figs. 1a,b). The geometric parameters associated with the configurations of $S_{\text {road }}$ and $S_{\text {alley }}$ are listed in Table 1.

In the experimental area, most of the roofs are flat and made of dark asphalt and tar (plus insulation material and wood in internal layers of the roofs). The exterior of the walls is made of bricks (plus insulation and wood in internal layers), whereas roads are made of asphalt (plus soil underneath). Thermal and radiative properties of these materials are prescribed from the literature data (ASHRAE 1981; Oke 1987; Mills 1993; Masson et al. 2002). For roads, the albedo can be defined using local observations obtained during the last IOP of the experiment (5 April 2005) over dry pavement free of snow. For pervious or natural covers, short grass is the dominant type of vegetation, together with a few trees. Soil texture is prescribed using the Soil Landscapes of
Canada database, provided by Agriculture and AgriFood Canada. The values of vegetation properties are those typically used for parks that include lawn and a few trees. It should be noted, however, that vegetation is still inactive during MUSE 2005 (i.e., March and April); therefore, the leaf area index is set to zero.

\section{c. Initial conditions for TEB-ISBA}

As much as possible, TEB-ISBA's prognostic variables are initialized by using measurements collected during MUSE 2005. Otherwise, these variables are specified from model outputs produced by Environment Canada's regional numerical weather prediction system (see Mailhot et al. 2006). This is notably the case for ISBA's soil temperatures and soil water contents that were not measured during the experiment. For TEB, surface temperatures for roofs are initialized from infrared camera data, whereas for roads, alleys, and walls, surface temperatures are obtained from IOP1 manual measurements. Internal building temperature is prescribed to a comfortable temperature of $20^{\circ} \mathrm{C}$. Finally, temperature deep under the pavement is specified using deep soil temperature from Environment Canada's regional model forecast. The previously defined variables are initialized in the same manner for both the $S_{\text {road }}$ and $S_{\text {alley }}$ simulations.

In contrast, most of the initial conditions for snow properties are different for the two simulations because snow cover as well as the state of snow aging were significantly different at the start of the experiment in the alleys and in the streets. Snow cover and properties were found to be more homogeneous in the alleys than in the streets, where human activities disturb the snowpack. The characteristics of snow in the streets were observed to be quite variable from one location to another (Ho 2002; Ho and Valeo 2005). For instance, snow on front yards was mostly undisturbed, in contrast with sidewalks where pedestrians walk, with road curbs where cars are parked, and with pavement where traffic takes place. Consequently, it is quite challenging to specify realistic mean snow properties for TEB's initialization, in particular for $S_{\text {road }}$.

Nevertheless, initial values of snow properties (snow depth, density, and albedo over ground-based built areas, pervious covers, and roofs) for $S_{\text {road }}$ and $S_{\text {alley }}$ were defined using as much data collected during IOP1 as possible, or according to simple assumptions when data are not available experimentally. This is discussed in further detail in section 5 a.

\section{Comparison of model outputs with observations}

Snow conditions rapidly evolve during the experiment from a near-total to a zero snow coverage fraction. The 
impact of these variations on radiation and energy budgets was discussed by Lemonsu et al. (2008), who compared the observed fluxes temporally averaged for three different periods: MUSE corresponds to the complete experimental period, except for the days when the tower was down or when it was raining; SNOW is a 4-day period (18-21 March) early in the experiment, characterized by a large snow cover; and NOSN is a 3-day period (911 April) later in the experiment when there is almost no more snow. Observations and model outputs are compared here using the same periods to assess the model performance under these different conditions.

\section{a. Energy budget}

The energy budget can be written as

$$
Q^{*}+Q_{F}=Q_{H}+Q_{E}+\Delta Q_{S}+Q_{M}+\Delta Q_{A},
$$

where $Q^{*}$ is the net radiation; $Q_{F}$ is the anthropogenic heat flux; $Q_{H}$ and $Q_{E}$ are the turbulent sensible and latent heat fluxes, respectively; $\Delta Q_{S}$ is the storage heat flux (in ground, artificial materials, and snow packs); $Q_{M}$ is the flux associated with the snowmelt process (no soil water freezing in this case); and $\Delta Q_{A}$ is the net advective heat flux. Because of the homogeneity of surface characteristics, $\Delta Q_{A}$ can be neglected here [as discussed in Lemonsu et al. (2008)].

The measurements provide $Q^{*}, Q_{H}$, and $Q_{E}$. The net radiation $Q^{*}$ is estimated from the radiation budget $Q^{*}=S^{\downarrow}+L^{\downarrow}-S^{\uparrow}-L^{\uparrow}$, with $S^{\downarrow}$ and $L^{\downarrow}$ being the short- and longwave downward radiation (used as forcing), and $S^{\uparrow}$ and $L^{\uparrow}$ being the short- and longwave upward radiation. The fluxes $Q_{H}$ and $Q_{E}$ are calculated using an eddy correlation technique. The residual term $Q_{\text {res }}$ is derived from the remaining components that cannot be directly measured, so that

$$
Q_{\mathrm{res}}=Q^{*}-Q_{H}-Q_{E}=\Delta Q_{S}+Q_{M}-Q_{F} \text {. }
$$

For the experimental site and the study period, $Q_{F}$ is quite small as compared with $\Delta Q_{S}$ and $Q_{M}$ (this will be discussed in section 5). As a result, $Q_{\text {res }} \simeq \Delta Q_{S}+Q_{M}$. For NOSN, $Q_{M}$ is assumed to be zero because there is no more snow and then $Q_{\text {res }}$ only depends on $\Delta Q_{S}$.

It is worth emphasizing that the experimental data contain some errors resulting from the instrumentation or measurement techniques. According to the literature, errors between $5 \%$ and $20 \%$ are noted for $Q^{*}$ (Kohsiek et al. 2007) and are of the order of $10 \%$ and $15 \%$ for $Q_{H}$ and $Q_{E}$, respectively (Mauder et al. 2007). It is also known that the eddy correlation method usually induces an underestimation of the turbulent heat fluxes (Foken et al. 2006), which can be partially attributed to local
TABLE 2. Statistical scores including bias (model - observed) and RMSE calculated from 30-min measurements and model outputs for energy budgets components $\left(\mathrm{W} \mathrm{m}^{-2}\right)$. These scores are calculated successively for MUSE, SNOW, and NOSN, and for each of these periods for all day, daytime $\left(Q^{*}>0\right)$, and nighttime

\begin{tabular}{|c|c|c|c|c|c|c|}
\hline & \multicolumn{3}{|c|}{ Bias } & \multicolumn{3}{|c|}{ RMSE } \\
\hline & MUSE & SNOW & NOSN & MUSE & SNOW & NOS \\
\hline \multicolumn{7}{|l|}{ All day } \\
\hline$Q^{*}$ & +1.3 & +3.5 & +0.9 & 6.5 & 13.4 & 9.9 \\
\hline$\widetilde{Q}_{H}$ & +19.5 & +2.2 & +32.1 & 38.8 & 8.5 & 67.6 \\
\hline$Q_{E}$ & -2.2 & -7.5 & +1.8 & 6.0 & 8.8 & 11.3 \\
\hline$Q_{\mathrm{res}}$ & -16.1 & +8.8 & -33.0 & 46.2 & 16.2 & 80.8 \\
\hline \multicolumn{7}{|c|}{ Daytime } \\
\hline$Q^{*}$ & -3.8 & -4.9 & -5.7 & 6.1 & 14.0 & 11.3 \\
\hline$\widetilde{Q}_{H}$ & +38.6 & -0.5 & +68.0 & 53.2 & 10.3 & 92.3 \\
\hline$Q_{E}$ & +0.8 & -9.1 & +8.7 & 6.3 & 10.2 & 14.5 \\
\hline$Q_{\mathrm{res}}$ & -43.2 & +4.6 & -82.4 & 62.1 & 18.2 & 109.0 \\
\hline \multicolumn{7}{|c|}{ Nighttime } \\
\hline$Q^{*}$ & +6.8 & +12.6 & +8.0 & 6.8 & 12.5 & 7.9 \\
\hline$Q_{H}$ & -1.2 & +5.2 & -7.0 & 3.0 & 5.5 & 10.6 \\
\hline$Q_{E}$ & -5.4 & -5.8 & -5.6 & 5.4 & 6.6 & 5.6 \\
\hline$Q_{\mathrm{res}}$ & +13.4 & +13.2 & +20.6 & 13.3 & 13.4 & 21.7 \\
\hline
\end{tabular}
$\left(Q^{*}<0\right)$ hours.

vertical advections caused by turbulent organized structures (Kanda et al. 2004; Steinfeld et al. 2007). Finally, the use of different measurement methods for radiation components and turbulent heat fluxes can also contribute to an energy budget closure problem. As a result, the residual term is associated with an uncertainty in a range of $0 \%-15 \%$, resulting from an accumulation of errors on the measurements of $Q^{*}, Q_{H}$, and $Q_{E}$. Although these measurement errors are not negligible, their orders of magnitude do not question the main results presented afterward.

Table 2 summarizes the bias and RMSE between the model results and observations for the MUSE, SNOW, and NOSN periods, and by separating daytime and nighttime hours. (Note that even though daytime and nighttime periods should be defined based on $S^{\downarrow}$, the net radiation $Q^{*}$ is used instead in this study in a manner consistent with the literature.)

According to MUSE averaged results (Fig. 3a), $Q^{*}$ is well simulated at daytime but slightly overestimated at night (with a bias of $+6.8 \mathrm{~W} \mathrm{~m}^{-2}$ as indicated in Table 2) because energy losses by infrared emissions are underestimated (not shown). It is also seen that the partitioning of the net radiation between $Q_{H}, Q_{E}$, and $Q_{\text {res }}$ is not well simulated by the model. During daytime, the simulation overestimates $Q_{H}\left(\right.$ bias $\left.=+38.6 \mathrm{~W} \mathrm{~m}^{-2}\right)$ while simulating a realistic $Q_{E}$. This leads to a strong underestimate of $Q_{\text {res }}$, in comparison with observations (bias $=-43.2 \mathrm{~W} \mathrm{~m}^{-2}$ ) for which $Q_{\mathrm{res}}$ is the predominant term of the energy budget. At night, $Q_{\text {res }}$ is overestimated (bias $=+13.4 \mathrm{~W} \mathrm{~m}^{-2}$ ). 

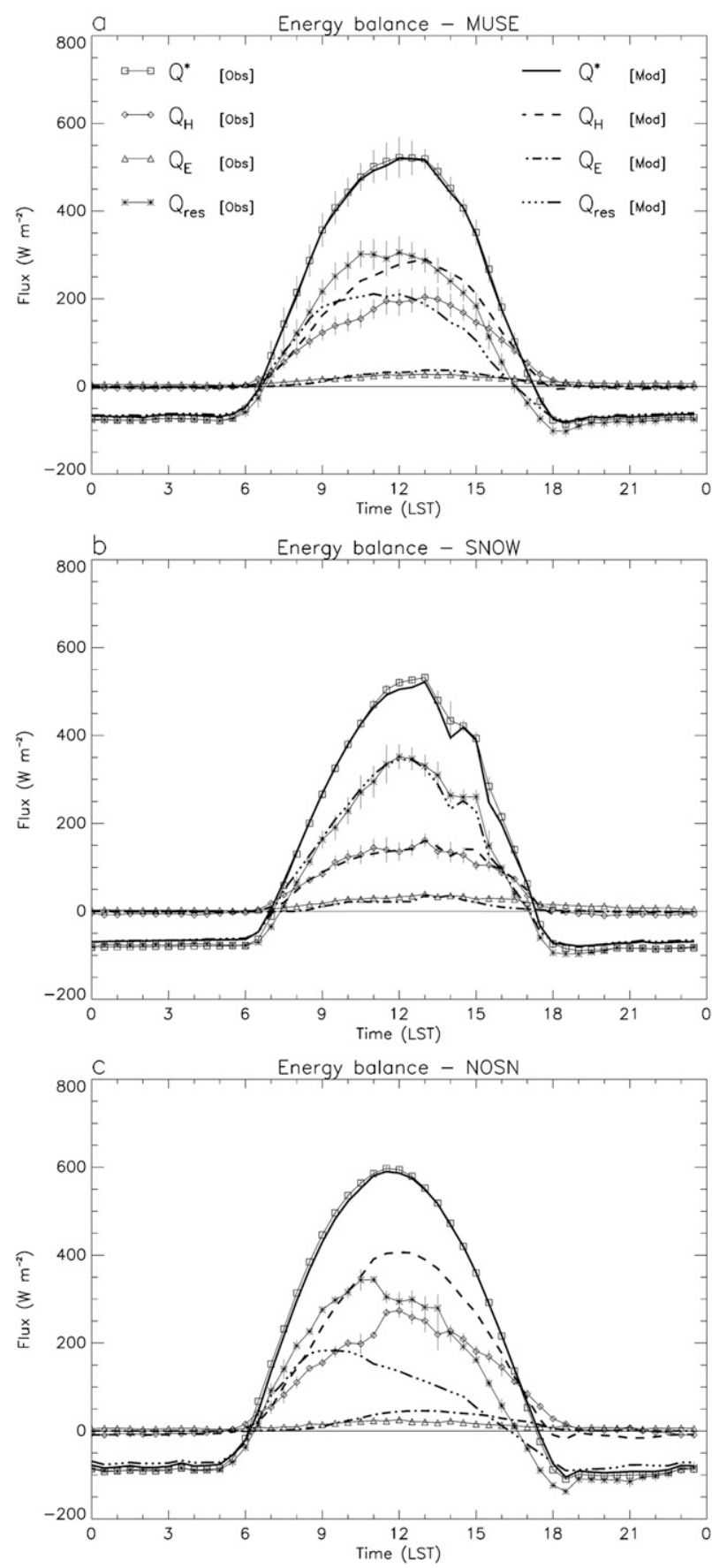

FIG. 3. Simulated and observed energy budgets $\left(\mathrm{W} \mathrm{m}^{-2}\right)$ averaged over the (a) MUSE, (b) SNOW, and (c) NOSN periods, using a 30-min time step. Vertical bars represent the standard deviations of observed fluxes.

When snow is present, the fluxes are very well simulated as shown by the SNOW energy budget (Fig. 3b); for instance, $Q_{H}$ and $Q_{\text {res }}$ daytime biases are equal to -0.5 and $+4.6 \mathrm{~W} \mathrm{~m}^{-2}$, respectively. It is worth noting, however, that the initial results for $Q_{E}$ (with values near zero) prompted us to reexamine the surface evaporation process in TEB. The quantity of snow that melts on roofs and on roads was lost for the system in the initial version of TEB. It is now transferred to the roof and road water reservoirs. The new latent heat flux $Q_{E}$ is in better agreement with observations, but it still remains a bit underestimated (daytime bias $=-9.1 \mathrm{~W} \mathrm{~m}^{-2}$ ). A detailed analysis of $Q_{\text {res }}$ still indicates differences between the model and observations. Even though it is very well simulated during daytime, $Q_{\text {res }}$ is overestimated during the night (bias $=+13.2 \mathrm{~W} \mathrm{~m}^{-2}$ ). In addition, the integral of $Q_{\text {res }}$ calculated over the SNOW period is positive for both the model and observations $(+47.9$ and $+39.1 \mathrm{~W} \mathrm{~m}^{-2}$, respectively) but larger in the model.

It was previously noted that $Q_{\text {res }}$ includes contributions from $\Delta Q_{S}$ and $Q_{M}$ (with $Q_{F}$ negligible). As a result,

$$
\int_{\mathrm{SNOW}} Q_{\mathrm{res}} d t=\int_{\mathrm{SNOW}} \Delta Q_{S} d t+\int_{\mathrm{SNOW}} Q_{M} d t
$$

The integral of $\Delta Q_{S}$ is usually close to zero over a diurnal cycle (even if some part of it can be used to warm the ground). With snow, $Q_{M}$ largely contributes to $Q_{\text {res }}$ during daytime but is zero at night (no melting). The integral of $Q_{M}$ is then positive and corresponds to energy loss for the system. It could, thus, be argued that the overestimation of $Q_{\text {res }}$ by the model during both daytime and nighttime indicates that the daytime $Q_{M}$ contribution is probably overestimated and, conversely, that the contribution of $\Delta Q_{S}$ is underestimated, leading to a lack of heat storage during daytime and a lack of heat release at night.

The weaknesses underlined by MUSE averaged results are amplified during the period without snow (NOSN; Fig. 3c) with daytime $Q_{H}$ and $Q_{\text {res }}$ biases of +68.0 and $-82.4 \mathrm{~W} \mathrm{~m}^{-2}$, respectively. In the model, the integral of $Q_{\text {res }}$ is close to zero $\left(+7.8 \mathrm{~W} \mathrm{~m}^{-2}\right)$ because the main contribution comes from $\Delta Q_{S}\left(Q_{M}=0\right)$. Surprisingly, the integral of $Q_{\text {res }}$ for observations is still largely positive $\left(+40.9 \mathrm{~W} \mathrm{~m}^{-2}\right)$ during the period without snow. Even if the model tends to underestimate the heat storage process, this cannot completely explain such a discrepancy. It seems that some process(es) is missing in order to understand the observed energy budget. This will be discussed further in section 5. Finally, NOSN daytime $Q_{E}$ is overestimated in the model (bias = $+8.7 \mathrm{~W} \mathrm{~m}^{-2}$ ). An analysis of model fluxes from TEB and ISBA indicates that ISBA produces too much evaporation from the ground when compared to observations.

\section{b. Snow properties}

Because ISBA and TEB snow schemes have never been specifically evaluated in urban environments, the 
MUSE 2005 dataset offers a first opportunity to estimate the values of some parameters used in the time evolution of snow depth, density, and albedo (see section 2). These include maximum snow density $\rho_{n}^{\max }$ and minimum snow albedo $\alpha_{n}^{\mathrm{min}}$, which limit darkening and compaction of snow during the aging process, and the time constant $\tau_{f}$ that sets the snow aging speed for the evolution of the snow density and albedo of (2) and (3). However, it is not possible to assess parameters for fresh snow characteristics (e.g., minimum snow density $\rho_{n}^{\min }$ and maximum snow albedo $\alpha_{n}^{\max }$ ) because no snowfall occurred during MUSE 2005. Likewise, within the framework of MUSE 2005, the time constant $\tau_{a}$ used for snow albedo during cold periods without snowmelt from (4) cannot be evaluated.

Snow density, depth, and albedo were directly measured during the experiment, whereas the snow cover fraction was estimated from analysis of infrared camera imagery. For ground-based built covers, snow depth and density were measured only where snow accumulation was large enough to allow manual measurements, that is, on front yards, at certain locations of sidewalks, and on both sides of the alley, and only during the first two IOPs. Such measurements were not feasible on main roads and on a large part of the sidewalks where snow was scattered, heterogeneous, and packed. The analysis of snow properties on the ground will, therefore, focus on the $S_{\text {alley }}$ results.

\section{1) SNOW PROPERTIES ON GROUND}

In agreement with snow albedo measured at the end of the experiment when snow is old and highly deteriorated (Fig. 4a), $\alpha_{n}^{\min }$ of alleys has been reset to 0.15 (a much lower value than 0.50 used in the original TEB formulation). This minimum value is consistent with those obtained experimentally by Bengtsson and Westerström (1992) in Lulea, Sweden, and by Ho (2002) in Calgary, Alberta, Canada. Over vegetation, snow albedo is assumed to become a bit less dark and is set to 0.20 . Similarly, $\rho_{n}^{\max }$ of $350 \mathrm{~kg} \mathrm{~m}^{-3}$ for both the alleys and vegetation (instead of $300 \mathrm{~kg} \mathrm{~m}^{-3}$ in D95) seems more consistent with the snow density increase observed between IOP1 and IOP2 (Fig. 4b). For time constant $\tau_{f}$ used in the snow albedo prognostic Eq. (3), the same observations in the alley suggest a more realistic value of 0.174 in an urban environment (instead of 0.240 for ISBA's snow scheme according to D95).

These modifications result in a fairly good simulation of the observed evolution of snow albedo and snow density (Figs. 4a,d). The snow albedo evolution in the alley (Fig. 4a) is also in good agreement with time-dependent albedo curves proposed by Valeo and Ho (2004) for Calgary. In particular, the curve obtained for road shoul- ders is quite similar to the one that is found for front yards during MUSE 2005, both experimentally and numerically.

Snow depth is deduced from simulated snow density and snow water equivalent. It decreases too rapidly in comparison with measurements done in the alley (Fig. 4c). This difference can probably be linked with the fact that measurements were conducted on the edges of the alley, which are shaded for a large part of the day. The photographs of the alleys taken during the campaign (see Fig. 5b in Lemonsu et al. 2008) indicate that the snowpack is spatially heterogeneous with smaller snow depth in the center of the alley. These disparities cannot be reproduced by the model, which simply represents an averaged snow depth. It was, thus, expected that simulated snow depths should be smaller than those experimentally obtained. Nonetheless, one can note that the simulation is more comparable with snow depth measured on sidewalks and front yards. These results, and notably the evolution of the snow fraction in the alley (Fig. 4d), show that complete snowmelt occurs too early in the simulation, that is, after 12 days. In contrast, the observations and the photographs indicate that a thin snowpack persists in the alley until 5 April. Finally, snow fraction over vegetation is also presented in this figure, although no measurement is available for comparison. However, our knowledge of the site indicates that in the simulation, snow melts too rapidly over vegetation as well.

\section{2) SNOW PROPERTIES ON ROOFS}

For roofs, only snow depth and snow cover fraction were measured during MUSE 2005. As a result, the values of the snow parameters and time constants $\left(\rho_{n}^{\max }, \alpha_{n}^{\min }\right.$, and $\tau_{f}$ ) cannot be directly evaluated. In a way similar to ground-based covers, it seems reasonable to assume that an appropriate value for $\tau_{f}$ is 0.174 . Time constant $\rho_{n}^{\max }$ is kept to $300 \mathrm{~kg} \mathrm{~m}^{-3}$ by assuming that snow compaction is more limited on roofs than on the ground in the urban environment. Finally, $\alpha_{n}^{\min }$ is set to 0.30 (instead of 0.15 for ground-based built covers and 0.20 for vegetation) because snow albedo decreases less rapidly on roofs since there is no alteration resulting from the pedestrians. According to snow depth data and estimates of snow cover fraction (Fig. 5), the snowpack melted very rapidly and snow completely disappeared on the roofs two-and-half days after the beginning of the experiment. The main features of this behavior are correctly reproduced by the model simulation.

\section{Energy budget residual term}

The objective of this section is to quantify the different contributions $Q_{M}, Q_{F}$, and $\Delta Q_{S}$ to the residual term $Q_{\text {res }}$ [according to Eq. (6)], using both measurements 

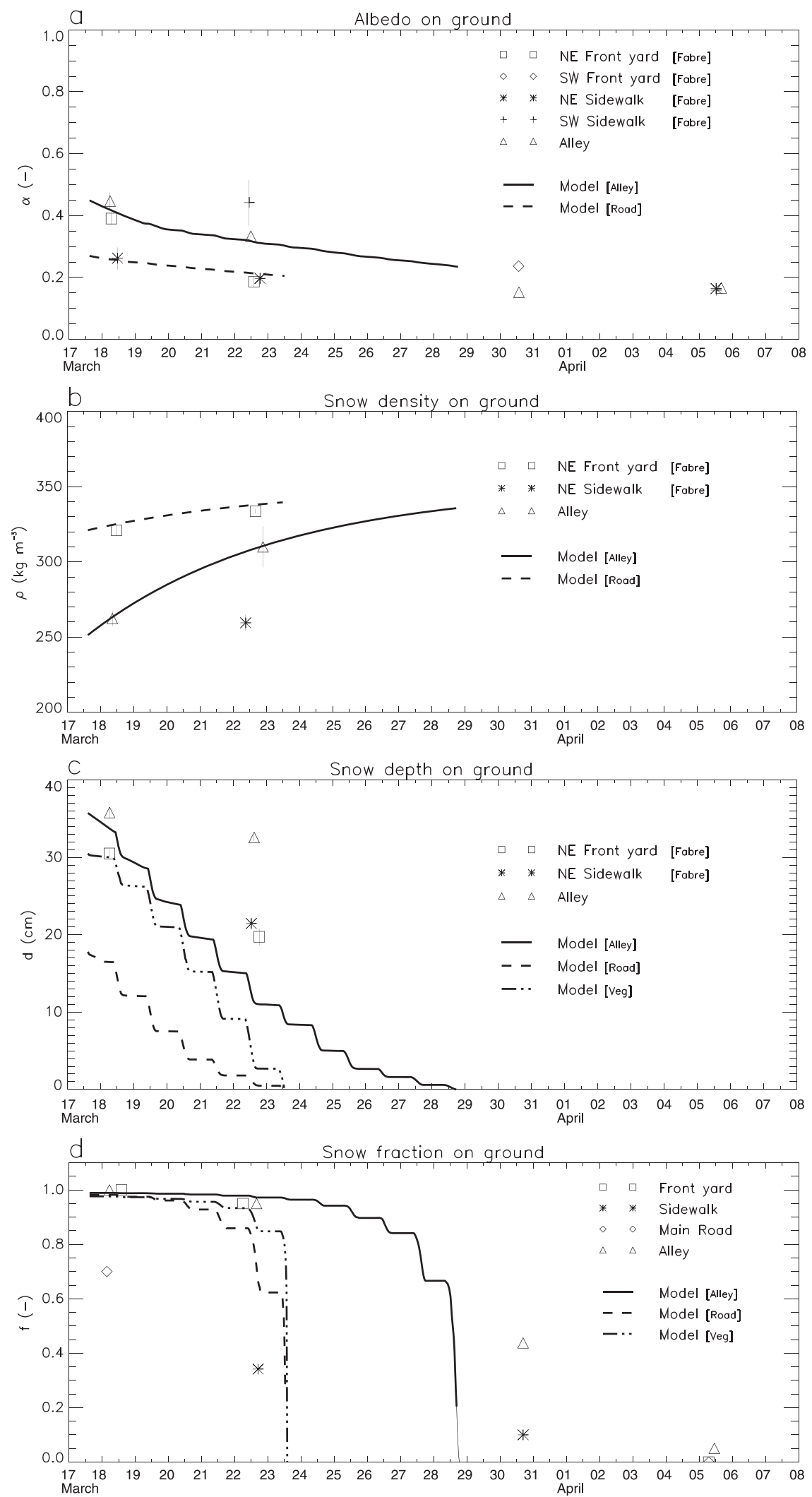

FIG. 4. Simulated and observed snow properties on the ground: (a) snow albedo (documented by manual measurements during IOPs), (b) snow density $\left(\mathrm{kg} \mathrm{m}^{-3}\right)$, (c) snow depth (cm), and (d) snow fraction estimated from infrared camera imagery. For the model outputs, snow properties from $S_{\text {road }}$ and from $S_{\text {alley }}$ are presented, as well as snow cover fraction on vegetation. 

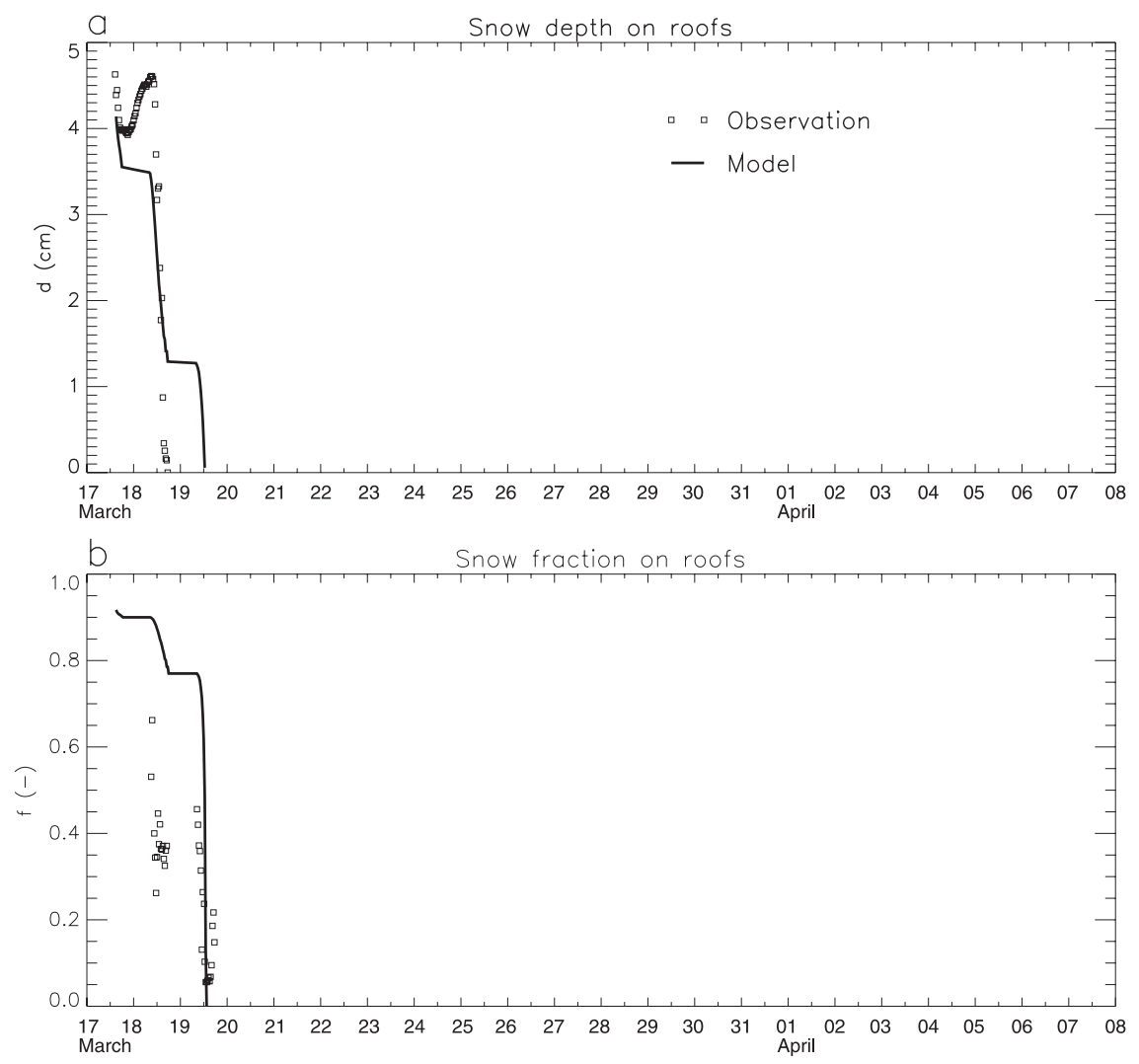

FIG. 5. Simulated and observed snow properties on the roof: (a) the snow depth $(\mathrm{cm})$, measured by remote sensor, and (b) the snow fraction, estimated from infrared camera imagery.

and modeling results. Numerically, both $Q_{M}$ and $Q_{F}$ are determined in the model. Experimentally, $Q_{M}$ is estimated using snow measurements conducted during IOPs, and $Q_{F}$ is quantified using electricity consumption data. For both the model and experiment, $\Delta Q_{S}$ is calculated as a residue $\left(\Delta Q_{S}=Q_{\text {res }}-Q_{M}-Q_{F}\right)$. Because there is not enough snow during IOP3 and IOP4 to characterize the snowpack, this study is focused on the period IOP1-IOP2 (i.e., from 17 to 22 March 2005).

\section{a. Estimation of snowmelt flux from observations}

The energy required to melt snow is evaluated experimentally by characterizing the snowpack temporal evolution between IOP1 and IOP2 on the different types of covers, using observations of $\rho_{n^{*}}$, snow depth $d_{n^{*}}$, and snow cover fractions $f_{n^{*}}$. For roofs, alleys, and front yards, snow measurements are directly available for IOP1 and IOP2. For roads, sidewalks, and backyards, snow properties are determined from three simple hypotheses. 1) For sidewalks and backyards, the snow density and depth are the same as for front yards (except for snow depth on sidewalk for IOP2 because it was directly measured). 2) For roads, snow properties are needed only for IOP1, because there was no more snow at the time of IOP2. Given the fact that this is the location where snow accumulation was the weakest, and considering the photographs of the roads taken during IOP1, snow depth is taken equal to $5 \mathrm{~cm}$. Snow density is the same as for front yards. 3) For roofs, snow density is assumed to be the same as in the alleys where snow is the least packed. All values are summarized in Table 3.

Snow water equivalent is obtained from $W_{n^{*}}=$ $d_{n^{*}} \rho_{n^{*}}$, and snowmelt flux is then determined as $Q_{M}^{n^{*}}=$ $\sum_{*}^{n *} f_{n^{*}} W_{n^{*}} L_{M} / \Delta t$, where $f_{*}$ is the fraction of cover type (* refers to the cover type), $f_{n^{*}}$ is the snow cover fraction, $L_{M}$ is the latent heat of fusion, and $\Delta t$ is the period in seconds. The energy used for snow melting is then estimated to be $19 \mathrm{~W} \mathrm{~m}^{-2}$ over the whole day.

To distribute this total energy according to a mean diurnal cycle, we assume that snowmelt occurs only when the surface temperature is greater than the melting point $T_{00}=273.16 \mathrm{~K}$. For the period IOP1-IOP2, the main snow-covered surfaces are the ground-based surfaces because the roofs are very rapidly free of snow. An averaged surface temperature is then estimated from manual surface temperature measurements recorded in 
TABLE 3. Snow properties evolution between IOP1 and IOP2 derived from IOPs measurement, and associated snowmelt flux for the IOP1-IOP2 period, estimated for the different natural (front yards and backyards) and built (roofs, roads, alleys, and sidewalks) covers.

\begin{tabular}{|c|c|c|c|c|c|c|c|c|c|c|}
\hline & \multicolumn{2}{|c|}{$d_{n}(\mathrm{~cm})$} & \multicolumn{2}{|c|}{$\rho_{n}\left(\mathrm{~kg} \mathrm{~m}^{-3}\right)$} & \multicolumn{2}{|c|}{$W_{n}\left(\mathrm{~kg} \mathrm{~m}^{-3}\right)$} & \multirow[b]{2}{*}{$f_{*}$} & \multicolumn{2}{|c|}{$f_{n}$} & \multirow{2}{*}{$\begin{array}{l}Q_{M}\left(\mathrm{~W} \mathrm{~m}{ }^{-2}\right. \\
\text { IOP1-IOP2 }\end{array}$} \\
\hline & IOP1 & IOP2 & IOP1 & IOP2 & IOP1 & IOP2 & & IOP1 & IOP2 & \\
\hline Roof & 4.40 & 0.00 & $251 *$ & - & 11.04 & 0 & 0.36 & 0.60 & 0.00 & -1.84 \\
\hline Front yard & 30.50 & 19.73 & 321 & 334 & 97.91 & 65.90 & 0.09 & 1.00 & 0.95 & -2.45 \\
\hline Sidewalk & $30.50 *$ & 21.45 & $321 *$ & $334 *$ & $97.91 *$ & $71.57 *$ & 0.15 & $1.00 *$ & 0.34 & -8.53 \\
\hline Road & $5.00 *$ & 0.00 & $321^{*}$ & - & $16.05^{*}$ & 0 & 0.15 & 0.70 & 0.00 & -1.30 \\
\hline Alley & 35.80 & 32.57 & 251 & 310 & 89.86 & 100.97 & 0.05 & 1.00 & 0.95 & +0.23 \\
\hline Backyard & $30.50 *$ & $19.73^{*}$ & $321^{*}$ & $334 *$ & $97.91 *$ & $65.90 *$ & 0.20 & $1.00 *$ & $0.95^{*}$ & $\begin{array}{r}-5.45 \\
-19.34\end{array}$ \\
\hline
\end{tabular}

* Values referring to snow properties that were not directly measured and that were deduced from measurements recorded on other types on covers.

the streets and in the alley during IOP1 and IOP2 (Fig. 6, top). The daily evolution of the "observed" snowmelt flux $Q_{M}$ is finally estimated by assuming that $Q_{M}$ is proportional to this surface temperature when it is greater than $T_{00}$. Otherwise, $Q_{M}$ is zero.

The simulated $Q_{M}$, averaged for the IOP1-IOP2 period compares well with this snowmelt flux deduced from observations (Fig. 6, bottom). The timing is good, but the magnitude is slightly overestimated (by about $+13 \%)$, more specifically in the morning. This confirms the overestimate that had already been noted in section 4a. This deficiency can be explained by a too-rapid snowmelt process over vegetation in the model (see also snow cover fraction evolution in Fig. 4a). Because ISBA is not directly coupled with TEB, it does not take into account the canyon geometry for resolving its radiation budget; however, it represents vegetated covers as open areas. Consequently, shadow effects inside canyons are not treated in ISBA, which tends to overestimate the incoming radiation over vegetation. Indeed, according to Semadeni-Davies and Bengtsson (1998) and SemadeniDavies et al. (2001), canyon effects tend to enhance or decrease the net all-wave radiation received by snowpacks located close to sun-lit or shaded walls, respectively. But on average, snowpacks receive less radiation.

\section{b. Estimation of anthropogenic heat flux from electricity consumption data}

Usually, anthropogenic heat flux $Q_{F}$ is assumed to include contributions from the human metabolism, domestic heating (or an air-conditioning system), and vehicle traffic. The human metabolism is negligible in comparison with other heat sources (Grimmond 1992; Sailor and $\mathrm{Lu}$ 2004). In the present case, the experimental area is located in a residential district and, therefore, the heat releases resulting from traffic are not considered as important. The analysis will then focus on energy consumption associated with domestic heating.
The quantity $Q_{F}$ is calculated from electricity consumption data provided by the Quebec electricity company Hydro-Québec by assuming that all domestic heating systems in the area are electric. Although this is not the case (oil and, to a much lesser extent, wood heating are also used), electric systems are used in the majority - that is, by $80 \%$ - of households in Montreal according to Statistics Canada (2007). Unfortunately, Hydro-Québec data are available only for the second experimental campaign (MUSE 2006) that took place during February-March 2006 in the same area as MUSE 2005. We use electricity consumption data for a period in March 2006 that corresponded closely to the temperature conditions observed during IOP1-IOP2.

Hydro-Québec provided hourly electricity consumption $E_{\text {elec }}(\mathrm{kW} \mathrm{h})$ for a two-story house. In view of the results of Lemonsu et al. (2008), this building can be assumed to be representative of the buildings that are located within the footprint of the measurements and that contribute to the heat releases resulting from the domestic heating. Indeed, the surface characteristics of the footprints, based on the analysis of the National Topographic Data Base (NTDB) from Geomatics Canada, indicate that the buildings are mainly two- and three-story houses, whereas the public and commercial buildings are negligible. According to the aerial photograph of the area, each block is composed of about 30 contiguous houses. The electricity consumed by a block can, thus, be deduced as the sum of the contributions from all the houses by assuming that each of them has approximately the same consumption. Finally, starting from the description of urban arrangement presented in Fig. $1 \mathrm{~b}$ and the associated cover fractions, this term can be translated as a flux expressed in watts per square meter.

This anthropogenic heat flux deduced from HydroQuébec data is referred to as $Q_{F_{H O}}$ and is shown in Fig. 7. The values of anthropogenic flux are surprisingly weak considering the cold climate of Montreal at this time of the year. They vary around $5 \mathrm{~W} \mathrm{~m}^{-2}$, which is much 


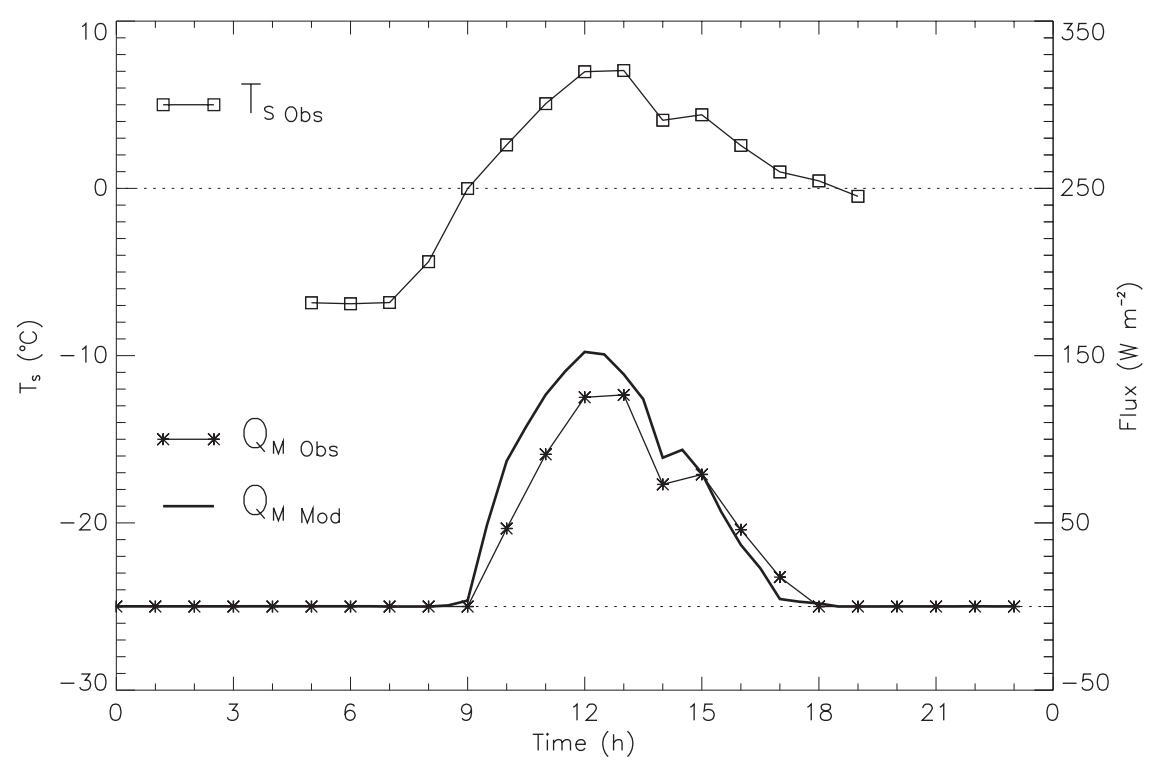

FIG. 6. Averaged surface temperature $\left({ }^{\circ} \mathrm{C}\right)$ computed from manual surface temperature measurements recorded in the streets and the alley during IOP1 and IOP2 (top curve). Daytime evolution of snowmelt flux $\left(\mathrm{W} \mathrm{m}^{-2}\right)$ modeled by TEB-ISBA and estimated from measurements during the IOP1-IOP2 period (bottom curves).

lower than what is usually found in the literature (e.g., Oke 1988; Kłysik 1996; Ichinose et al. 1999; Sailor and Lu 2004; Pigeon et al. 2007). They are more comparable to the anthropogenic fluxes (not taking into account traffic emissions) obtained by Grimmond (1992) and Makar et al. (2006) for residential areas of Vancouver.
The flux $Q_{F_{\mathrm{HO}}}$ follows a diurnal cycle with two maxima, one at around 0700 LST and one at around 1900 LST.

The model diagnoses an anthropogenic flux $Q_{F_{\text {Mod }}}$ calculated as the flux required to maintain a comfortable temperature for inhabitants of $20^{\circ} \mathrm{C}$ inside buildings (Pigeon et al.2008). This flux is averaged over the period

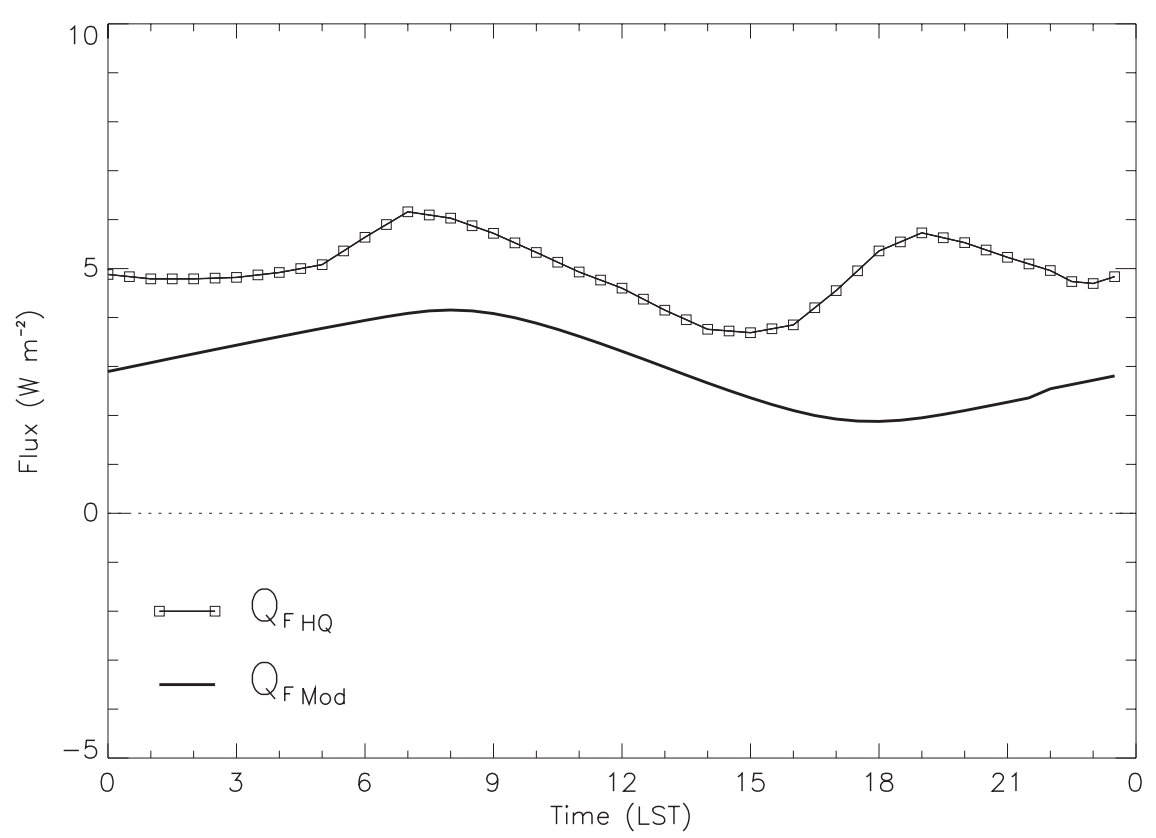

FIG. 7. Simulated and observed anthropogenic heat flux $\left(\mathrm{W} \mathrm{m}^{-2}\right)$ averaged during the IOP1-IOP2 period. 

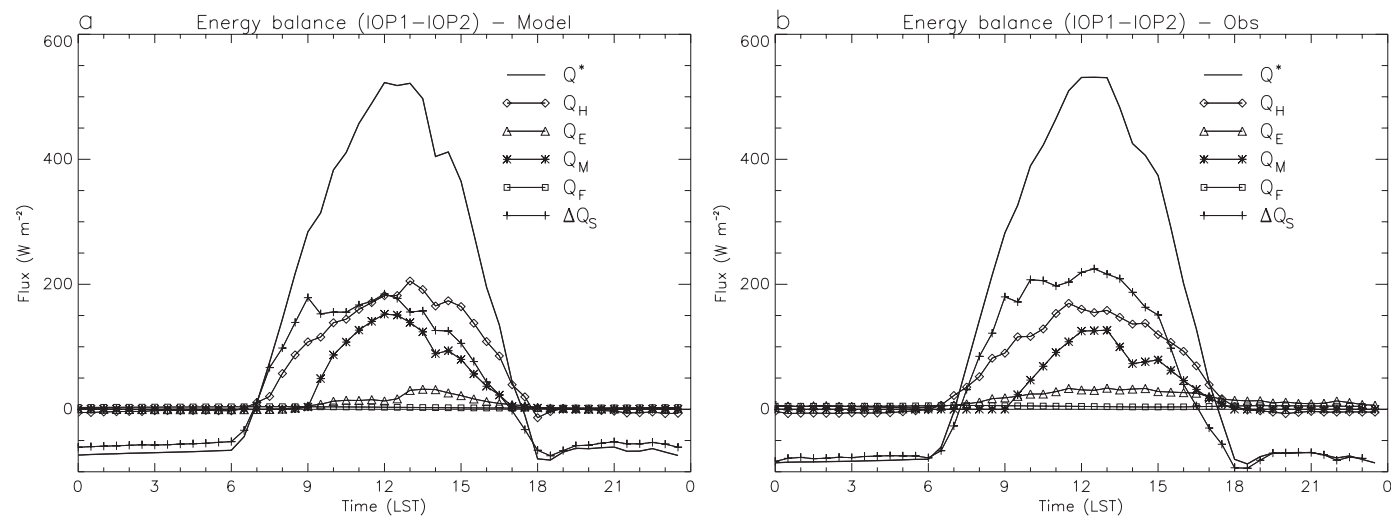

FIG. 8. (a) Simulated and (b) observed energy budgets $\left(\mathrm{W} \mathrm{m}^{-2}\right)$ averaged over the IOP1-IOP2 periods using a 30-min time step. For model outputs, all contributions are presented, that is, sensible and latent heat fluxes, snowmelt flux, anthropogenic heat flux, and storage heat flux.

IOP1-IOP2 (Fig. 7). It follows a diurnal cycle that is directly linked to the daily evolution of the outside air temperature, but with a delay of a couple of hours resulting from the heat conduction process from the inside to the outside of the buildings. The simulated anthropogenic flux $Q_{F_{\mathrm{Mod}}}$ is a bit lower than $Q_{F_{\mathrm{HO}}}$ but of the same order of magnitude (Fig. 7). This corroborates the hypothesis that the anthropogenic flux is rather weak in this district of Montreal, which is probably a result of the construction standards (several federal programs encouraged housing renovations and thermal insulation in the 1970s and 1980s). Finally, one can note that the model does not reproduce the peak observed in the evening because it only takes into account the domestic heating, not the other types of electricity consumption (e.g., lighting or home appliances).

\section{c. Estimation of storage heat flux and analysis of energy budget}

The storage heat flux $\Delta Q_{S}$ includes contributions for heat storage inside the ground, snowpacks, and built structures. With the previously mentioned estimates of $Q_{M}$ and $Q_{F}, \Delta Q_{S}$ can now be determined as the residue of the energy budget [following Eq. (5)]:

$$
\Delta Q_{S}=Q^{*}+Q_{F}-\left(Q_{H}+Q_{E}+Q_{M}\right)
$$

Simulated $\Delta Q_{S}$ is computed following the same method and averaged over the IOP1-IOP2 period. The complete energy budget, including all the contributions expressed in Eq. (5) (except $\Delta Q_{A}$ that is neglected), is presented in Fig. 8 for both the observations and model outputs. The mean daytime partitioning is also calculated for daytime hours of the same period (Table 4) by computing the ratio between the various energy sinks
$\left(Q_{H}, Q_{E}, Q_{M}\right.$, and $\left.\Delta Q_{S}\right)$ and the net quantity of energy received by the system $\left(Q^{*}+Q_{F}\right)$.

Observations indicate that the main contributions come from the heat storage process $(42 \%)$ and the sensible heat flux (33\%). The snowmelt flux represents $17 \%$ of $Q^{*}+Q_{F}$ and the latent heat flux is only $7 \%$. Finally, the anthropogenic heat flux is negligible because it only contributes $1 \%$. This partitioning is quite similar to the one obtained for SNOW in section 4a, at least for $Q_{H}$, $Q_{E}$, and $Q_{\text {res }}$, because at this stage, $Q_{\text {res }}$ was not decomposed in distinct contributions.

Although TEB-ISBA correctly simulates the SNOW energy budget (see section $4 \mathrm{a}$ and Fig. $3 \mathrm{~b}$ ), it tends to overestimate the daytime sensible heat flux for the IOP1-IOP2 period, with $39 \%$ of $Q^{*}+Q_{F}$ instead of $33 \%$ in observations, probably because the snow melts too rapidly over vegetation between IOP1 and IOP2 (see Figs. 4a,b). Latent heat flux associated with evaporation/sublimation of melting snow is still a bit underestimated (4\% instead of 7\%), but the values of $Q_{E}$ are quite small. According to the results presented previously, TEB-ISBA simulates a realistic snowmelt flux $Q_{M}$, but it is a bit too large (22\% instead of $17 \%$ ), and an anthropogenic heat flux $Q_{F}$ comparable to the observations. Here, $\Delta Q_{S}$ computed as the residue is underestimated ( $36 \%$ instead of $42 \%)$; this bias is being mainly driven by an overestimate of $Q_{H}$.

TABLE 4. Simulated and observed flux partitioning calculated for the daytime hours of the IOP1-IOP2 period.

\begin{tabular}{lcc}
\hline \hline & Obs & Model \\
\hline$Q_{H} /\left(Q^{*}+Q_{F}\right)$ & 0.33 & 0.39 \\
$Q_{E} /\left(Q^{*}+Q_{F}\right)$ & 0.07 & 0.04 \\
$Q_{M} /\left(Q^{*}+Q_{F}\right)$ & 0.17 & 0.22 \\
$Q_{F} /\left(Q^{*}+Q_{F}\right)$ & 0.01 & 0.01 \\
$\Delta Q_{S} /\left(Q^{*}+Q_{F}\right)$ & 0.42 & 0.36 \\
\hline
\end{tabular}


It is, however, important to note that by taking into account the measurement uncertainties (presented in section $4 \mathrm{a}$ ), the observed contributions can be significantly different. By assuming an underestimation of $15 \%$ of $Q_{H}$ and $Q_{E}$ and an overestimation of $15 \%$ of $\Delta Q_{S}$ (because it is deduced as the residue), their contributions become equal to $38 \%, 8 \%$, and $36 \%$, respectively. These results are in better agreement with the simulated contributions.

\section{Summary and conclusions}

The TEB-ISBA modeling system is evaluated over a heavily populated residential area of Montreal during the winter-spring transition, using the MUSE 2005 database. Results are analyzed by separating periods with and without snow to evaluate the performance of the system under these different conditions.

The study of the energy budget at different periods of MUSE 2005 shows a much better agreement between model results and observations when the snow cover is still important, rather than during the last days when snow is almost melted. TEB-ISBA predicts a realistic partitioning between the turbulent fluxes $Q_{H}$ and $Q_{E}$ and the residual term $Q_{\text {res }}$, when surfaces are snow covered. At this period of the year, $Q_{\text {res }}$, which includes the contributions of storage heat flux $\Delta Q_{S}$, snowmelt flux $Q_{M}$, and anthropogenic heat flux $Q_{F}$, is mainly driven by the snowmelt processes. The energy budget is correctly simulated by TEB-ISBA on average, although the snow melts too rapidly over vegetation. This defect can be attributed to an overestimation of the incident radiation received by vegetation in ISBA because the shading caused by buildings is not taken into account in the current version of TEB-ISBA.

The evaluation of the simulated energy budget when snow is melted exhibits several discrepancies. In this case, according to the observations, the contribution of $\Delta Q_{S}$ becomes dominant but is underestimated by the model in favor of the sensible heat flux (and of the latent heat flux in a lesser extent). Nevertheless, this process alone cannot explain the very high $Q_{\text {res }}$ observed during daytime. The fact that the daily integral of $Q_{\text {res }}$ is largely positive suggests that an additional mechanism is acting as an important sink of energy for the system during daytime. At this stage, one plausible process could be the effects of the freezing and thawing of water in the soil. This issue is currently studied in more detail using the MUSE 2006 database (Leroyer et al. 2010). However, the overestimation of $Q_{H}$ and $Q_{E}$, associated with the underestimation of $Q_{\text {res }}$ by TEB-ISBA in comparison to the observations, may be partially attributed to errors in the measurements. It is known that the turbu- lent heat fluxes calculated using the eddy correlation techniques are usually underestimated, leading to an energy budget closure problem.

Temporal evolution of snow cover and snow properties by TEB-ISBA is also studied. The very rapid snowmelt observed on roofs is well simulated by the system, as well as the decrease of snow albedo and the increase of snow density with time on ground-based built surfaces. In contrast, the snow depth in the alleys and the streets is underestimated, which can be attributed to the fact that the measurements were done on the edges of roads and alleys, whereas the model simulates a spatially averaged snow depth.

Finally, the analysis of the residual term of the energy budget for the IOP1-IOP2 period, based on snow properties, observations, and ancillary data (such as electricity consumption), has allowed us to broadly quantify the different contributions resulting from snowmelt, heat storage, and anthropogenic heat releases. The results indicate that the anthropogenic heat flux is negligible compared to the other processes. Although the snowmelt component is considerable during this period $(17 \%$ of net radiation during daytime), storage heat flux remains dominant $(42 \%)$. Simulated fluxes are compared to this data and confirm that TEB-ISBA underestimates the storage heat flux.

This work presents encouraging results but also underlines some major modeling issues that have to be investigated. Some of TEB's assumptions should be questioned, such as the definition of a single urban canyon or the isotropy of street orientations. The inclusion of vegetation inside the streets, already in progress, is also an important development. In addition, we are working on a better representation of snow in TEB and ISBA for the urban environments, more particularly by coupling the models to more advanced snow schemes (e.g., Boone and Etchevers 2001; Bélair et al. 2003b; Bouilloud and Martin 2006) than the D95 snow parameterization. Several improvements are planned, notably the explicit representation of snow cover heterogeneities on roads, the inclusion of the snowpack stratification that is not possible with D95, and a more realistic treatment of anthropogenic impacts (e.g., snow plowing, deicer use, effects of road traffic, and pedestrians).

Such studies are strongly constrained by data availability. Although MUSE 2005 provided an original and interesting database of snow properties, additional observations are required to better characterize the spatial heterogeneity of snow and to document snow in the gardens. The study period should also be extended to cold episodes with snowfalls. This is the case of the field campaign MUSE 2006 (Leroyer et al. 2010) and the project Environmental Prediction in Canadian Cities 
(EPiCC; Voogt et al. 2009). Finally, specific attention must be concentrated on the characterization of anthropogenic heat fluxes.

Acknowledgments. The authors are grateful to Frédéric Chagnon and Gilles Morneau for their assistance in the analysis of the experimental data. The support of MSC management, in particular Gilbert Brunet and Richard Hogue, is warmly acknowledged. This work was funded by the Chemical, Biological, Radiological, and Nuclear (CBRN) Research and Technology Initiative (CRTI) (Project 02-0093RD) of Defence Research and Development Canada.

\section{REFERENCES}

Allwine, K. J., M. J. Leach, L. W. Stockham, J. S. Shinn, R. P. Hosker, J. F. Bowers, and J. C. Pace, 2004: Overview of Joint Urban 2003-An atmospheric dispersion study in Oklahoma City. Preprints, Symp. on Planning, Nowcasting, and Forecasting in the Urban Zone, Seattle, WA, Amer. Meteor. Soc., J7.1. [Available online at http://ams.confex.com/ams/84Annual/ techprogram/paper_74349.htm.]

ASHRAE, 1981: ASHRAE Handbook: 1981 Fundamentals. American Society of Heating, Refrigerating, and Air-Conditioning Engineers, Inc., 800 pp.

Baker, D. G., D. L. Ruschy, and D. B. Wall, 1990: The albedo decay of prairie snows. J. Appl. Meteor., 29, 179-187.

Bélair, S., L.-P. Crevier, J. Mailhot, B. Bilodeau, and Y. Delage, 2003a: Operational implementation of the ISBA land surface scheme in the Canadian regional weather forecast model. Part I: Warm season results. J. Hydrometeor., 4, 352-370.

_ , R. Brown, J. Mailhot, B. Bilodeau, and L.-P. Crevier, 2003b: Operational implementation of the ISBA land surface scheme in the Canadian regional weather forecast model. Part II: Cold season results. J. Hydrometeor., 4, 371-386.

Bengtsson, L., and G. Westerström, 1992: Urban snowmelt and runoff in northern Sweden. Hydrol. Sci. J., 37, 263-275.

Best, M. J., 1998: A model to predict surface temperatures. Bound.Layer Meteor., 88, 279-306.

Boone, A., and P. Etchevers, 2001: An intercomparison of three snow schemes of varying complexity coupled to the same land surface model: Local-scale evaluation at an alpine site. J. Hydrometeor., 2, 374-394.

_ J.-C. Calvet, and J. Noilhan, 1999: Inclusion of a third soil layer in a land surface scheme using the force-restore method. J. Appl. Meteor., 38, 1611-1630.

Bouilloud, L., and E. Martin, 2006: A coupled model to simulate snow behavior on roads. J. Appl. Meteor. Climatol., 45, 500-516.

Brown, M. J., 2000: Urban parameterizations for mesoscale meteorological models. Mesoscale Atmospheric Dispersion, Z. Boybeyi, Ed., Wessex Press, 193-255.

Douville, H., J.-F. Royer, and J.-F. Mahfouf, 1995: A new snow parameterization for the Météo-France climate model. I: Validation in stand-alone experiments. Climate Dyn., 12, 21-35.

Dupont, S., T. L. Otte, and J. K. S. Ching, 2004: Simulation of meteorological fields within and above urban and rural canopies with a mesoscale model (MM5). Bound.-Layer Meteor., 113,111-158.

Foken, T., F. Wimmer, M. Mauder, C. Thomas, and C. Liebethal, 2006: Some aspects of the energy balance closure problem. Atmos. Chem. Phys., 6, 4395-4402.
Grimmond, C. S. B., 1992: The suburban energy balance methodological considerations and results for mid-latitude west coast city under winter and spring conditions. Int. J. Climatol., 12, 481-497.

— , and T. R. Oke, 2002: Turbulent heat fluxes in urban areas: Observations and local-scale urban meteorological parameterization scheme (LUMPS). J. Appl. Meteor., 41, 792-810.

,-- , and D. G. Steyn, 1986: Urban water balance. 1. A model for daily totals. Water Resour. Res., 22, 1397-1403.

Ho, C. L. I., 2002: Urban snow hydrology and modelling. M.S. thesis, Dept. of Geomatics Engineering, University of Calgary, $145 \mathrm{pp}$

- , and C. Valeo, 2005: Observations of urban snow properties in Calgary, Canada. Hydrol. Processes, 19, 459-473.

Ichinose, T., K. Shimodozono, and K. Hanaki, 1999: Impact of anthropogenic heat on urban climate in Tokyo. Atmos. Environ., 33, 3897-3909.

Kanda, M., A. Inagaki, M. O. Letzel, S. Raasch, and T. Watanabe, 2004: LES study of the energy imbalance problem with eddy covariance fluxes. Bound.-Layer Meteor., 110, 381-404.

Kłysik, K., 1996: Spatial and seasonal distribution of anthropogenic heat emissions in Łódź, Poland. Atmos. Environ., 30, 3397-3404.

Kohsiek, W., C. Liebethal, T. Foken, R. Vogt, S. Oncley, C. Bernhofer, and H. Debruin, 2007: The Energy Balance Experiment EBEX-2000. Part III: Behaviour and quality of the radiation measurements. Bound.-Layer Meteor., 123, 55-75.

Kusaka, H., H. Kondo, Y. Kikegawa, and F. Kimura, 2001: A simple single-layer urban canopy model for atmospheric models: Comparison with multi-layer and slab models. Bound.-Layer Meteor., 101, 329-358.

Lemonsu, A., C. S. B. Grimmond, and V. Masson, 2004: Modeling the surface energy budget of an old Mediterranean city core. J. Appl. Meteor., 43, 312-327.

, and Coauthors, 2008: Overview and first results of the Montreal Urban Snow Experiment 2005. J. Appl. Meteor. Climatol., 47, 59-75.

— S. Bélair, and J. Mailhot, 2009: The new Canadian urban modelling system: Evaluation for two cases from the Joint Urban 2003 Oklahoma City experiment. Bound-Layer Meteor., 133, 47-70.

Leroyer, S., J. Mailhot, S. Bélair, A. Lemonsu, and I. Strachan, 2010: Modeling the surface energy budget during the thawing period of the 2006 Montreal Urban Snow Experiment. J. Appl. Meteor. Climatol., 49, 68-84.

Mailhot, J., and Coauthors, 2006: The 15-km version of the Canadian regional forecast system. Atmos.-Ocean, 44, 133-149.

Makar, P. A., S. Gravel, V. Chirkov, K. B. Strawbridge, F. Froude, J. Arnold, and J. Brook, 2006: Heat flux, urban properties, and regional weather. Atmos. Environ., 40, 2750-2766.

Martilli, A., A. Clappier, and M. Rotach, 2002: An urban surface exchange parameterization for mesoscale models. Bound.Layer Meteor., 104, 261-304.

Masson, V., 2000: A physically based scheme for the urban energy budget in atmospheric models. Bound.-Layer Meteor., 94, 357-397.

, C. S. B. Grimmond, and T. R. Oke, 2002: Evaluation of the Town Energy Balance (TEB) scheme with direct measurements from dry districts in two cities. J. Appl. Meteor., 41, 1011-1026.

Mauder, M., and Coauthors, 2007: The energy balance experiment EBEX-2000. Part II: Intercomparison of eddy-covariance sensors and post-field data processing methods. Bound.-Layer Meteor., 123, 29-54. 
Mills, G., 1993: Simulation of the energy budget of an urban canyon. I: Model structure and sensitivity test. Atmos. Environ., 27B, 157-170.

_- 1997: An urban canopy-layer climate model. Theor. Appl. Climatol., 57, 229-244.

Noilhan, J., and S. Planton, 1989: A simple parameterization of land surface processes for meteorological models. Mon. Wea. Rev., 117, 536-549.

—_, and J.-F. Mahfouf, 1996: The ISBA land surface parameterization scheme. Global Planet. Change, 13, 145-159.

Offerle, B., P. Jonsson, I. Eliasson, and C. S. B. Grimmond, 2005: Urban modification of the surface energy balance in the West African Sahel: Ouagadougou, Burkina Faso. J. Climate, 18, 3983-3995.

Oke, T. R., 1987: Boundary Layer Climates. 2nd ed. Methuen, 435 pp.

_ 1988: The urban energy balance. Prog. Phys. Geogr., 12, 471-508.

Pigeon, G., D. Legain, P. Durand, and V. Masson, 2007: Anthropogenic heat release in an old European agglomeration (Toulouse, France). Int. J. Climatol., 27, 1969-1981.

_ M. A. Moscicki, J. A. Voogt, and V. Masson, 2008: Simulation of fall and winter surface energy balance over a dense urban area using the TEB scheme. Meteor. Appl. Phys., 102, 159-171.

Roberts, S. M., T. R. Oke, C. S. B. Grimmond, and J. A. Voogt, 2006: Comparison of four methods to estimate urban heat storage. J. Appl. Meteor. Climatol., 45, 1766-1781.

Sailor, D. J., and L. Lu, 2004: A top-down methodology for developing diurnal and seasonal anthropogenic heating profiles for urban areas. Atmos. Environ., 38, 2737-2748.
Semadeni-Davies, A., and L. Bengtsson, 1998: Snowmelt sensitivity to radiation in the urban environment. Hydrol. Sci. J., 43, 67-89.

_ A. Lundberg, and L. Bengtsson, 2001: Radiation balance of snow in the urban environment: A water management perspective. Cold Reg. Sci. Technol., 33, 59-76.

Statistics Canada, 2007: Survey of household spending (SHS), dwelling characteristics at the time of interview, by province, territory and selected metropolitan areas, annual. Table 2030019. [Available online at http://cansim2.statcan.ca/cgi-win/ cnsmcgi.exe Lang $=\mathrm{E} \&$ RootDir $=\mathrm{CII} / \&$ ResultTemplate $=$ CII/CII_pick\&Array_Pick $=1 \&$ ArrayId $=203-0019$.]

Steinfeld, G., M. Letzel, S. Raasch, M. Kanda, and A. Inagaki, 2007: Spatial representativeness of single tower measurements and the imbalance problem with eddy-covariance fluxes: Results of a large-eddy simulation study. Bound.-Layer Meteor., 123, $77-98$

Valeo, C., and C. L. I. Ho, 2004: Modelling urban snowmelt runoff. J. Hydrol., 299, 237-251.

Verseghy, D. L., 1991: CLASS-A Canadian land surface scheme for GCMS. 1. Soil model. Int. J. Climatol., 11, 111-133.

Voogt, J. A., and Coauthors, 2009: The Environmental Prediction in Canadian Cities (EPiCC) network. Preprints, Eighth Symp. on the Urban Environment, Phoenix, AZ, Amer. Meteor. Soc., J1.4. [Available online at http://ams.confex.com/ams/89annual/ techprogram/paper_148928.htm.]

Vu, T. C., Y. Ashie, and T. Asaeda, 2002: A k- $\epsilon$ turbulence closure model for the atmospheric boundary layer including urban canopy. Bound.-Layer Meteor., 102, 459-490. 